\title{
Movimentos de mudança na formação em saúde: da medicina comunitária às diretrizes curriculares
}

\section{| ${ }^{1}$ Alberto Durán González, ${ }^{2}$ Marcio José de Almeida |}

Resumo: Este ensaio busca refletir as diversas iniciativas pró-mudança na formação superior em saúde implantadas no Brasil. Esta análise histórica faz-se necessária tendo em vista a importância da sistematização e difusão das experiências anteriores para o auxilio na construção das novas propostas pró-mudança. Estamos hoje refletindo sobre processos ativos de ensino-aprendizagem por termos vivenciado propostas como a da Medicina Comunitária, o Projeto de Integração Docente Assistencial, o Programa UNI, o movimento da Rede UNIDA, a Lei de Diretrizes Curriculares, Educação Permanente em Saúde e o Curso de Ativadores. Avançamos a partir da construção da tentativa anterior. Não é necessária a descoberta da roda a todo momento. Ela pode ser adaptada e voltar a girar. O olhar para as experiências do passado e para as necessidades do presente ajuda na construção do futuro almejado.

> Palavras-chave: Educação em Saúde; Política de Saúde; Formação de Recursos Humanos; Movimento Pró-Mudança na Formação.

\author{
1 Farmacêutico, professor \\ da Universidade Estadual de \\ Londrina. Mestre em Saúde \\ Coletiva pela Universidade \\ Estadual de Londrina. Endereço \\ eletrônico: betoduran_fbq@ \\ yahoo.com.br \\ ${ }^{2}$ Médico, professor da \\ Universidade Estadual de \\ Londrina. Doutor em Saúde \\ Pública pela Faculdade de \\ Saúde Pública/Universidade de \\ São Paulo.
}

Recebido em: 13/03/2009 Aprovado em: 05/05/2010.

*Artigo baseado em dissertação do curso de Mestrado em Saúde Coletiva da Universidade Estadual de Londrina. Apoio financeiro do Conselho Nacional de Desenvolvimento Científico e Tecnológico - CNPq por meio do processo 408938/2006-4. 
No âmago do processo educativo do país, este estudo enfoca o ensino superior em saúde, que, ainda hoje, apresenta fortes influências da concepção flexneriana e da fragmentação dos conhecimentos durante os processos de ensino-aprendizagem.

O final do século XIX traz o avanço científico e com isso a substituição do empirismo, da tentativa e erro, pelo método científico. A rápida proliferação de práticas assistenciais forçou a reflexão de um processo de contenção regulamentada. Surge então a figura de Abraham Flexner, médico americano, que assume, em 1910, um amplo estudo sobre a educação médica norte-americana. Esse enorme trabalho impactou decisivamente sobre o aparato formador, disciplinando-o e reduzindo o número de instituições de ensino. O chamado Relatório Flexner, além de influenciar o ensino norte-americano, influenciou a prática médica mundial, consolidando o paradigma da medicina científica, que orientou e que ainda orienta em muitos lugares o ensino e as práticas profissionais na área da saúde ao longo de todo o século XX. Suas principais características são: a segmentação em ciclos básico e profissional, o ensino baseado em disciplinas ou especialidades e ambientado em sua maior parte dentro de hospitais (SAKAI et al., 2001; GIL et al., 1996).

O modelo flexneriano começou a ser implantado no Brasil na década de 40, influenciando os novos cursos de Medicina, Odontologia e Enfermagem, além de reformular os cursos já existentes (FEUERWERKER; MARSIGLIA, 1996). Paradoxalmente, o rápido e contínuo desenvolvimento científico-tecnológico conduziu o modelo flexneriano ao topo e o derrubou do mesmo. Os crescentes gastos, o consumo desenfreado das possibilidades de diagnóstico e tratamento em contraste com a escassez de recursos para o custeio são pontos marcantes à derrocada deste modelo, principalmente em países pobres ou em desenvolvimento (SAKAI et al., 2001; SANTANA; CAMPOS; SENA, 1999).

Para Morin (2005, 2006a), a formação universitária tem-se constituído no sentido de separar os objetos de seus contextos, conteúdos se dividem em disciplinas que não se integram e que são incapazes de entender a complexidade da realidade. Como consequência, apresenta uma efetiva perda da substância inventiva e criativa.

A introdução do "Estado de Bem-Estar Social" nos países europeus e, principalmente, a Medicina Social na Inglaterra, impulsionaram aos Estados Unidos a repensar e discutir a questão da assistência médica. Surge então a proposta da reforma preventivista e da medicina integral, sendo base doutrinária 
desse projeto o modelo da história natural da doença desenvolvido por Leavell e Clark (1976), incluindo nas ações os não-enfermos, englobando a saúde no processo saúde-doença (SANTANA; CAMPOS; SENA, 1999).

$\mathrm{Na}$ década de 50, esse grande movimento chega à América Latina, com um forte apoio financeiro de fundações filantrópicas. Os anos 50 ficaram marcados, inicialmente, pelos seminários de Viña del Mar, no Chile e de Tehuacán, no México. Posteriormente, pelo surgimento dos departamentos de Medicina Preventiva, por forte influência da Organização Pan-Americana de Saúde, em Cali, na Colômbia, e em Ribeirão Preto, no Brasil, que fizeram com que a preocupação com o trabalho comunitário saísse do campo das ideias para o campo das ações (SANTANA; CAMPOS; SENA, 1999; FEUERWERKER; MARSIGLIA, 1996; CHAVES, 1994). Surgiram então dois grandes movimentos pró-mudança na formação superior dos profissionais de saúde, o da Medicina Comunitária e o da Integração Docente-Assistencial (IDA). Esses movimentos surgem com o objetivo de responder às limitações de acesso ao sistema de serviços que amplia sua tecnologia e seus gastos (SANTANA; CAMPOS; SENA, 1999; CHAVES, 1994).

A Medicina Comunitária buscava uma medicina simplificada, retornando no tempo, buscando a medicina anterior à grande explosão tecnológica. Buscava também a inclusão diferenciada das camadas sociais marginalizadas pelo processo de desenvolvimento. Sua principal estratégia era o estímulo à participação comunitária, especialmente do trabalho voluntário. São exemplos desse movimento os feltshers, na ex-União Soviética, os "médicos de pés descalços", na China, e as experiências patrocinadas pela Aliança para o Progresso dos Estados Unidos realizadas na América Latina (SANTANA; CAMPOS; SENA, 1999).

Cabe aqui lembrar que as coisas não surgem e muito menos desaparecem no nada. Sempre existe um fio que liga todo o movimento, existe uma continuidade no processo (CHAVES, 1994). Os projetos de medicina comunitária surgiram, predominantemente, nos departamentos de medicina preventiva, eximindo os docentes dos departamentos clínicos de qualquer ação conjunta à comunidade (CHAVES, 1994). Esta ideia persiste até hoje em muitos lugares, onde as açôes extramuros hospitalares são exclusividade dos departamentos de medicina preventiva e social. Isto pode acontecer pela imposição dos próprios departamentos, que se sentem no dever de participar de todas as atividades externas, ou pela omissão dos demais departamentos. 
O movimento IDA associa-se aos movimentos anteriores e agrega a tática de quebrar a resistência dos estudantes à abordagem epidemiológica e social, inserindo o estudante no serviço através de atividades de extensão. A inserção do ensino no serviço deu-se de modo acelerado, principalmente nos anos 70, quando estágios práticos eram realizados em centros de saúde e hospitais. No entanto, essas estratégias não modificaram o ensino hospitalocêntrico e a prática fragmentada em inúmeras especialidades (FEUERWERKER; MARSIGLIA, 1996; MARSIGLIA, 1995).

Para Christofaro (1999), os processos maniqueístas e excludentes do sistema educacional tornaram a formação na área da saúde imprecisa e desordenada. A busca pela qualidade não alcançada pela formação durante a graduação passou a se dar no nível de pós-graduação - as especializaçōes. Se a pós-graduação é capaz de resgatar a qualidade não alcançada na formação superior, é uma hipótese ainda a ser demonstrada. Contudo, devemos ter em mente os desvios desta opção: primeiramente, a pequena parcela absorvida pela especialização; em um segundo momento, a finalidade da pós-graduação não pode ser a de preencher dos vazios da graduação. A pós-graduação deve ser encarada como uma educação continuada, sendo, portanto, espaço de aperfeiçoamento, atualização e aprofundamento de conhecimentos a priori, sendo impossível aperfeiçoar o que não se tem.

No final da década de 70, fica claro a todos os envolvidos nesse movimento que o avanço apenas se daria com iniciativas abrangentes ainda mais integradas e focadas na formação dos novos profissionais de saúde (FEUERWERKER; MARSIGLIA, 1996). Esforços visando a estimular a participação multidepartamental e multiprofissional no projeto IDA foram implementados pela Fundação Kellogg no fim da década de 70 e início da década de 80 (CHAVES, 1994).

Embora não se tenha atingido o objetivo final, muito se caminhou na direção de um ensino e de uma assistência mais adequada à realidade da sociedade. Realizou-se então a Reunião de Alma-Ata em 1978, quando a massa crítica formada no movimento e seus ideais foram amplamente discutidos, resultando em avanços reformistas, principalmente a estratégia da Atenção Primária de Saúde, e levando a fortes reformas em vários países. Surge aí o movimento de Reforma Sanitária no Brasil (SANTANA; CAMPOS; SENA, 1999; FEUERWERKER; MARSIGLIA, 1996).

A Organização Mundial de Saúde, após a reunião de Alma-Ata, reforçou o movimento que buscou a expansão da atenção primária à saúde e, já nesta reunião, 
destacou-se a importância do agente comunitário de saúde, além da ênfase dada ao trabalho comunitário e a articulação entre os vários setores de desenvolvimento social, o trabalho intersetorial. Demonstrou-se que tudo influencia a saúde e a saúde tudo influencia (CHAVES, 1994; WHO, 1978).

Após Alma-Ata, passou-se a discutir como inserir o trabalho universitário no serviço de saúde e chegou-se à ideia de que o serviço precede a universidade e esta não deve pretender estruturá-lo. Concluiu-se que a IDA estava limitada e que a expressão "Integração Docente-Assistencial" não demonstrava o que realmente se objetivava na prática. Chaves (1994) evoluiu no terreno conceitual, identificando que como não existe integração, o melhor termo seria "articulação". Se a aprendizagem é o objetivo final do docente, esse deveria ser o termo usado. Por fim, assistencial remete a ideias isoladas de açóes curativas, enquanto que o melhor termo deveria levar em conta a promoção de saúde e o autocuidado. O autor não buscou a alteração da expressão IDA quando colocou este pensamento; o que almejava era uma melhor compreensão do que se pretendia atingir por trás dos termos utilizados, os conceitos e os objetivos. Busca explanar que a Rede IDA "[...] trata-se de articulação, trata-se de aprendizagem e trata-se de abordagem integral dos problemas de saúde.” (CHAVES, 1994, p. 6).

A saúde no Brasil sofreu fortes mudanças nas décadas de 1980 e 1990, com a criação de um sistema universal, o Sistema Único de Saúde (SUS). São grandes os obstáculos na consolidação do SUS, apesar de ser o sistema de saúde vigente, amparado na Constituição Federal de 1988 e regulamentado pelas Leis Orgânicas de 1990. Seus princípios democráticos trabalham diretrizes, conceitos e práticas que eram e ainda são contra-hegemônicos na sociedade (MERHY; FEUERWERKER; CECCIM, 2006). O sistema hegemônico, o chamado modelo flexneriano, apresenta a atenção à saúde centrada na assistência curativa, hospitalar e superespecializada, na vertente de interesses econômicos e corporativos. A substituição desse sistema pelo sistema universal, que busca modelos de atenção que valorizem a integralidade, o cuidado humanizado e a promoção da saúde, depende do perfil de formação e da prática dos profissionais de saúde (ALMEIDA et al., 2005; FEUERWERKER, 1998).

Um desafio como este demanda a necessidade de quatro grandes vetores desafiantes: o vetor da formação, colocando em evidência o gerenciamento da educação; o vetor da atenção, que evidencia o gerenciamento da assistência; o vetor 
da gestão coloca em evidência o gerenciamento da administração e suporte. Por último, o vetor da participação, em que se evidencia o gerenciamento das relações com os usuários das açōes e serviços de saúde. Nesse contexto, a qualificação e o comprometimento dos profissionais de saúde tornam-se mais que simples necessidades, transformam-se em aspectos vitais para a real consolidação do SUS (CECCIM, 2002). O pleno direito à saúde depende de uma transformação das condições de vida, com uma radical mudança no modelo de atenção, onde se assuma a concepção mais ampla de saúde, sendo a promoção da mesma a linha mestra dessa transformação.

Muito se falou da importância da comunidade nos projetos IDA, porém mesmo presente nos projetos, a comunidade não estava presente na sigla IDA e muito menos nas estruturas de poder da IDA. E aí cabe o questionamento: a comunidade era vista como um ator no processo ou como um espaço à atuação? Quando se passa a pensar a IDA dos anos 90, os projetos UNI transformam-se no grande foco das atenções. São vistos como os grandes protagonistas para a mudança de paradigma, uma espécie de arcabouço conceitual do pensamento, do trabalho e ação no setor saúde. Nesse momento histórico, os conceitos utilizados anteriormente já não eram mais adequados, não explicavam a realidade e não facilitavam o trabalho em saúde. O choque com o crescimento dos custos da assistência à saúde, a insuficiência e a desumanização da atenção à saúde fizeram com que a necessidade de mudança na formação e a participação efetiva da comunidade na elaboração e monitoramento do processo ficassem ainda mais evidentes (CHAVES, 1994).

Deve-se levar em consideração que a relação profissional de saúde-usuário muitas vezes se dá como uma relação paternalista. É mais fácil ter um "pai" que guie do que assumir a responsabilidade de ser seu próprio líder e guia. Nessas relaçôes se expressam as diferentes formas de dominação e de poder (BLANK DE GARCIA, 1998). Nesse contexto, cabe tanto à população quanto aos profissionais de saúde e educação superarem elementos-chave para desempenhar seus papéis na busca do bem-estar. Faz-se necessário estabelecer uma concepção de saúde que expresse as múltiplas relações internas e externas, assim como sua capacidade de projeção emancipadora (BLANK DE GARCIA, 1998). Somente quando a comunidade se sentir parte do sistema e responsável por ele, se comprometerá e buscará mais que seus direitos, buscará seus deveres. 
Para muitos autores, a configuração constitucional irreversível do SUS deveria, necessariamente, ter gerado em todo setor responsável pela formação dos trabalhadores em saúde, uma imediata e profunda transformação no sentido de melhor enfrentar os novos desafios que se aproximavam rapidamente (GARRAFA, 1996). Uma real comunicação e uma relação potencializadora entre os Ministérios da Saúde e da Educação são ansiosamente esperadas por todos os envolvidos e compromissados com a formação superior (GARRAFA, 1996; TEIXEIRA; PAIM, 1996).

Demonstrando a força da categoria médica e sua postura compromissada, em 1991, a ABEM (Associação Brasileira de Ensino Médico) e o Conselho Federal de Medicina constituíram, com mais nove instituiçõos relacionadas, a Comissão Interinstitucional Nacional de Avaliação das Escolas Médicas (CINAEM), com o objetivo de avaliar o ensino nas escolas médicas. Esta iniciativa atingiu uma importante parcela dos docentes e um contingente bastante significativo dos estudantes, conseguindo colocar em movimento um número representativo de atores e sujeitos (SANTOS, 2000).

A CINAEM desenvolveu um projeto que contava com três fases: a primeira, levantando o perfil das escolas médicas brasileiras por meio de um instrumento adaptado do protocolo de avaliação elaborado pela Organização Pan-Americana de Saúde. Na segunda fase, os focos foram o médico formado, o corpo docente e o modelo pedagógico, sendo esta fase não só de pesquisa, mas também de ação, por meio de oficinas e treinamento de docentes e discentes. Ao final desta segunda etapa, formalizou-se a entrega dos relatórios de trabalho aos ministros de Educação e Saúde. Os resultados encontrados demonstravam a inadequação da formação frente às demandas da sociedade e a confirmação da presença do paradigma hegemônico do ensino centrado no professor, a superespecialização e as ações voltadas ao setor terciário (STELLA, 2002). Somente em 1998, deu-se início a terceira fase do projeto, denominada "Transformação do ensino médico no Brasil", que objetivou a melhor adequação da formação frente às necessidades de saúde da população (CECCIM; CARVALHO, 2005; LAMPERT, 2004), Segundo Carvalho (2001), com a conclusão da terceira etapa, a CINAEM conseguiu apontar sugestôes consistentes para a reformulação do ensino da medicina.

Em paralelo ao movimento médico, desenvolveram-se estudos, por meio de projetos isolados nas profissóes, sobretudo as desenvolvidas durante o movimento 
IDA. Os resultados desses estudos exigiram reflexão da Fundação Kellogg em dois pontos. O primeiro, no sentido de que a estratégia de articulação ensino-serviço deve ser repensada buscando envolver equipes multiprofissionais durante todo o curso de graduação. O segundo ponto reflete a pouca participação da comunidade, que deve ser estimulada para que se dê de forma consciente e de maneira corresponsável (FEUERWERKER; SENA, 2002; KISIL; CHAVES, 1994).

Levando em conta estas constataçôes, a Fundação Kellogg, no princípio da década de 90, iniciou um novo programa: o Programa UNI, "uma nova iniciativa em educação das profissões da saúde: união com a comunidade", que levou em consideração os pontos observados (LINS; CECILIO, 1998; MACHADO; CALDAS JR; BORTONCELLO, 1997, KISIL, 1996). Seu principal objetivo era o desenvolvimento de estratégias para intensificar o necessário processo de mudança na formação dos profissionais de saúde (FEUERWERKER; SENA, 2002; FEUERWERKER; MARSIGLIA, 1996).

Mediante o Programa UNI, pretendia-se mudar a formação das profissões de saúde, repensar a universidade, torná-la relevante para a sociedade; aplicar a produção acadêmica, relevante, na sociedade, mas com ações na comunidade, com a comunidade e para a comunidade, tornando a comunidade efetivo ator dentro do processo, com direitos e responsabilidades. A resistência à participação da comunidade se deu muito mais nas universidades que no serviço. Transformar divagações teóricas em açōes, mais que pensar e refletir, é um passo a frente, é agir (CHAVES, 1994).

O Programa UNI representou a conjunção de três movimentos que já estavam em marcha isoladamente. Essa união era condição para o desenvolvimento do mesmo. A Fundação Kellogg buscou acelerar o processo, convergindo os três movimentos: IDA, Atenção Primária de Saúde e a Extensão Comunitária (CHAVES, 1994; KISIL; CHAVES, 1994). Fundamentava-se na relação entre os componentes universidade, serviço e comunidade, analisando constantemente suas inter-relações por meio de uma abordagem holística e sistêmica. Ocorreu assim uma evolução nos projetos IDA e nos novos projetos UNI, a passagem de programas para problemas (FEUERWERKER; SENA, 2002; ALMEIDA, 1999). Sendo importante a interdisciplinaridade na universidade e a multiprofissionalidade nos serviços e na comunidade, rediscutiu a hegemonia médica, a articulação no trabalho multissetorial, e concluiu que a aprendizagem interdisciplinar facilita o trabalho multiprofissional e integral (LINS; CECILIO, 1998). 
O acréscimo do ideário UNI aos projetos IDA que já estavam em marcha ampliou a massa crítica dos projetos brasileiros, através de largos passos em direção à união entre os três grandes componentes e atores do movimento prómudança: universidade, serviço e comunidade (KISIL, 1996; CHAVES, 1994). Chaves (1994) afirma que o programa UNI é um programa IDA ampliado e que a única variável constante é o processo de mudança. Sendo a implantação e absorção do projeto pela realidade do serviço o grande objetivo a ser alcançado, o financiamento não deve ser visto como o suporte da ideia do projeto, mas como um catalisador no processo de absorção do projeto pela realidade.

O programa UNI possuiu novos propósitos, tais como: a parceria, o desenvolvimento de lideranças, a institucionalização, o desenvolvimento da comunicação e do trabalho em rede, o desenvolvimento da avaliação interna dos projetos, a pertinência, o desenvolvimento acadêmico, dos serviços e comunitário. Dos 23 projetos implantados na América Latina e no Caribe, seis foram implantados no Brasil. Mais especificamente, em Londrina-PR, Botucatu-SP, Marília-SP, Brasília-DF, Salvador-BA e Natal-RN (SCHMIDT, 2002; TANCREDI, 1995). Contudo, a área de desenvolvimento social está repleta de projetos inovadores que não obtiveram força suficiente para se instalar e provocar mudanças permanentes, muitas vezes por problemas nos processos de institucionalização das práticas inovadoras, outras vezes por problemas na sustentabilidade dos impulsos transformadores e, na maioria das vezes, por dificuldades em ambas dimensões (TANCREDI, 1995).

Como afirma Tancredi (1995), muitas vezes inebriados com os avanços conquistados com o projeto, seja pelo apoio financeiro ou pelo incremento na motivação, avaliadores e dirigentes acabam por se enredar com a euforia do hoje e se perdem no planejamento do amanhã. Com isso, as instituições formadoras de ensino superior têm perpetuado modelos essencialmente conservadores, centrados nas tecnologias altamente especializadas, dependentes de procedimentos e equipamentos de apoio diagnóstico e terapêutico (BLEJMAR; ALMEIDA, 1999).

A Rede IDA e os Projetos UNI são grandes exemplos de movimentos prómudança na formação superior dos profissionais de saúde, que buscavam responder aos anseios da população insatisfeita com os serviços de saúde prestados por profissionais formados de maneira não condizente com a realidade do SUS. Esses 
movimentos obtiveram êxitos limitados, mas se apresentaram como importantes avanços em seus momentos. Boa parte da realidade e da insatisfação se manteve, e a fragmentação do processo de trabalho ainda pode ser observada em várias dimensões - a separação entre o pensar e o fazer; a fragmentação conceitual; a presença cada vez maior de profissionais especializados, a fragmentação técnica; e as rígidas relações de hierarquia e subordinação, a fragmentação social -, configurando, assim, a divisão social do trabalho entre as diferentes categorias profissionais (FAGUNDES; FRÓES BURNHAM, 2005; ROSCHKE; DAVINI; HADDAD, 1994). O grande desafio está na quebra do continuísmo da fragmentação e na inclusão da integralidade e da humanização das práticas ainda durante a formação.

Com esse grande desafio em mente, surgiu em 1997 um novo movimento, com o foco voltado para a elaboração de propostas inovadoras para a formação e desenvolvimento dos profissionais de saúde. Como os integrantes de novo movimento provinham dos movimentos IDA e UNI, esse novo movimento passou a ser conhecido como Rede UNIDA (SCHMIDT, 2002; RANGEL; VILASBÔAS, 1996).

A Rede UNIDA, trabalhando em rede, visa a potencializar as capacidades de produzir mudanças, especialmente se elas são construídas, de forma coletiva, a partir do saber e do poder compartilhados. Com isso, ações e esforços isolados são transformados e potencializados em movimentos articulados. A Rede UNIDA consiste em um movimento que reúne pessoas, projetos e instituições comprometidos com os movimentos de mudanças na formação, o desenvolvimento dos profissionais de saúde e a construção de um sistema de saúde equitativo e eficaz, com forte participação social (FEUERWERKER, 2000; RANGEL; VILASBÔAS, 1996).

A discussão das Diretrizes Curriculares foi vista como uma oportunidade favorável à ação da Rede UNIDA, não apenas na estimulação do debate que se organizava de maneira isolada nas instituições de ensino em saúde, mas também se vislumbrou a possibilidade de mobilizar os setores da saúde para que passassem a influir, de modo mais organizado, na definição do perfil profissional mais adequado à necessidade da sociedade.

A necessidade de articulação interministerial e o compromisso de uma política de Estado, e não uma política de governo, mostram-se fundamentais para a implantação e real implementação de uma nova educação em saúde. Visando 
a um melhor entendimento e uma discussão mais coerente, faz-se importante

apresentar neste momento o conceito de mudança norteador ao estudo, sendo a definição adotada inicialmente por Kisil (1998, p. 6):

Mudança é um rompimento, mesmo que de forma gradual, com o status quo organizacional. A mudança pode ser consequência natural dos acontecimentos históricos e dos fatores que incidem sobre a organização, mas pode ser decorrente de adaptações às mudanças que ocorrem nos ambientes.

Associando este conceito ao tema do ensino superior de profissionais de saúde, busca-se identificar e caracterizar algumas das políticas pró-mudança; políticas que visaram ou visam a mudanças na formação superior em saúde. Tem-se, portanto, a superação da visão fragmentada, voltada para a formação tecnicista e especializada, com ensino baseado na transmissão do conhecimento e o aluno como sujeito passivo desse processo, para uma visão integral de saúde e de ensino, na qual o aluno se torna ator fundamental do processo ensino-aprendizagem e o foco é a interação com a complexa realidade (IVAMA; BATISTA; SILVA, 1997).

Não se pode refletir sobre os serviços de saúde sem considerar as relações entre seus atores ou sujeitos (L'ABBATE, 1994). Afinal, o atendimento envolve interação, que pode se dar como uma boa relação onde os dois lados assumem seus compromissos, cobram seus direitos e agem de acordo com seus deveres; ou apenas interagem sem compromisso ou reflexão.

As mudanças necessitam ser profundas e permanentes. Todos os envolvidos necessitam ter a consciência do processo e do produto que se planeja alcançar. Mais do que consciência, necessitam se comprometer com o projeto, assumir a ideia como sendo sua e trabalhar o ambiente, interno e externo, para alcançar os resultados sobre alicerces firmes e sólidos.

Ressalta-se que não se pode esperar uma reorientação espontânea das instituições de ensino, ou do serviço, na direção assinalada pelo SUS. Para favorecer o movimento, torna-se vital conferir direção convergente aos inúmeros processos de mudança, a fim de facilitar a consecução dos objetivos propostos, sempre com o foco no SUS, sem se esquecer dos interesses individuais, apenas colocando-os depois do interesse coletivo.

O trabalho interministerial entre o Ministério da Saúde e o Ministério da Educação construiu em 2006, com a coleção $A$ trajetória dos cursos de graduação na saúde: 1991-2004 e com o livro Dinâmica das graduaçôes em saúde no Brasil: 
subsidios para uma politica de recursos humanos, um panorama crítico que pretendia ser a linha de base para novas políticas orientadas para a mudança. A mudança deve acontecer em dois centros: no serviço, focado nos profissionais já formados e atuantes, e na academia, focado nos novos profissionais que irão compor o quadro de trabalhadores do SUS no futuro. Não cabe esperar a formação para que seja feita a adequação a prática do serviço; essa adequação deve ser concomitante e constante, afinal, a realidade não é estática. Entretanto, a observação da mudança na realidade deve ser pautada pela academia tanto quanto no serviço.

A mudança de paradigma na formação superior dos profissionais de saúde vem sendo estimulada através de políticas públicas. Apresentam-se em seguida algumas destas políticas pró-mudança, optando-se por abordar as políticas aplicadas no ensino superior da área da saúde.

O perfil dos egressos da formação superior na área da saúde passou, e ainda passa, por ampla discussão dentro do cenário brasileiro. A construção das DCNs - diretrizes curriculares nacionais dos cursos de graduação da área da saúde ocorreu em momento privilegiado da nossa sociedade. Diversos atores sociais contribuíram para a elaboração das DCN em todo o país. Ressalta-se que cada profissão teve suas diretrizes publicadas separadamente, sendo que as DCNs foram aprovadas, para os 14 cursos da área da saúde, entre 2001 e 2004. As DCN buscavam construir um perfil acadêmico e profissional com competências, habilidades e conteúdos de acordo com as necessidades atuais das populações, bem como para atuarem com qualidade e resolutividade no SUS (PEREIRA; LOPES; LUGARINHO, 2006).

A medicina teve suas DCNs aprovadas no final de 2001 e, já em 2002, por meio da parceria entre os Ministérios da Saúde e Educação e a Organização PanAmericana da Saúde, foi lançado o Programa de Incentivo a Mudanças Curriculares nos Cursos de Medicina (PROMED). Política pública que fortalecia o movimento de mudança na formação médica, o PROMED contou com a participação ativa da Associação Brasileira de Educação Médica e da Rede Unida durante sua construção coletiva, entendimentos políticos e trabalhos técnicos (SIQUEIRA, 2002).

Esse programa incentiva a implantação e consolidação das mudanças necessárias na formação médica, buscando atender às necessidades da sociedade e do setor saúde em conformidade com as diretrizes curriculares nacionais. $\mathrm{O}$ PROMED enfatiza a medicina preventiva, valorizando o conceito de saúde em 
detrimento da doença, a atenção básica e a humanização do atendimento por meio de uma sólida base ética (SCHMIDT, 2004). O PROMED selecionou 19 escolas médicas que desenvolveram ou desenvolvem suas atividades de mudança na formação profissional de forma pouco articulada entre si.

A criação do Departamento da Educação na Saúde (DEGES) como parte da estrutura da Secretaria de Gestão do Trabalho e da Educação na Saúde (SEGETS), em 2003, demonstrou que o Ministério da Saúde passou a priorizar a mudança na formação superior. O DEGES possui a função de motivar e propor açôes em duas grandes áreas: a mudança na formação técnica, de graduação e de pós-graduação e a educação permanente dos trabalhadores da saúde a partir das necessidades de saúde da população e de fortalecimento do SUS (BRASIL, 2006a).

Já em 2004, foi instituída a política nacional de educação permanente em saúde (EPS) como estratégia do SUS para a formação e o desenvolvimento de trabalhadores para o setor. A partir de então, para viabilizar essa política, iniciouse o processo de implantação dos polos de educação permanente em saúde. Constituídos por locorregiões, os polos são instâncias colegiadas que servem para a articulação, o diálogo, a negociação e a pactuação interinstitucional (BRASIL, 2007a). Para Ceccim (2005), a EPS é um processo de aprendizagem que promove a reflexão sobre as práticas do cotidiano. Os polos seriam os espaços coletivos para essa reflexão, envolvendo participantes do segmento de gestores, formadores, profissionais do serviço e do controle social.

Cabe destacar que, em agosto de 2007, a portaria no 1.996 Gabinete Ministerial/ Ministério da Saúde extinguiu os polos como instâncias de articulação regional e interinstitucional, passando a condução regional da política de EPS para os colegiados de gestão regional com a participação das comissões permanentes de integração ensino-serviço (CIES). A portaria ainda alterou a forma de planejamento e de financiamento da política. A efetivação da nova portaria certamente implicará novos arranjos para o fortalecimento da política de EPS (BRASIL, 2007b).

Os Ministérios da Saúde e Educação lançaram em 2004 o AprenderSUS - o SUS e os cursos de graduação da área da saúde (BRASIL, 2004a). O objetivo era de apoiar a gestão do ensino em coerência com as diretrizes e os princípios constitucionais do SUS e a implementação das diretrizes curriculares nacionais para os cursos de graduação na área da saúde. As diferentes estratégias para impulsionar a mudança na graduação compreendiam o VERSUS (Vivência-Estágio na Realidade 
do SUS), a convocatória de experiências de integralidade na formação em saúde, o Curso de Especialização em Ativação de Processos de Mudança nas Profissões da Área da Saúde e a possibilidade de apoio à implementação de estratégias de mudança, entre outros (LUGARINHO; FEUERWERKER, 2006).

O curso de ativação buscava suprir a necessidade de sistematizar e socializar as experiências acumuladas na área de mudança na formação em saúde para a efetiva implantação do AprenderSUS (FEUERWERKER; LIMA, 2004; FIOCRUZ, 2005). O contexto bastante favorável facilitou a inédita parceria entre DEGES/SGTES/Ministério da Saúde, ENSP e a Rede UNIDA, realizada em 2004. Esta aproximação viabilizou a implantação da política de incentivo do AprenderSUS, da qual o curso era uma das estratégias. Esse curso se diferencia das ações anteriores por ter sido construído coletivamente e por se caracterizar como um incentivo qualificador dos atores envolvidos e não apenas uma ação financiadora de grupos isolados. Teve por objetivo, além dos já citados, ampliar o número de pessoas qualificadas para ativação e condução de mudança no maior número de profissões e instituições de ensino possíveis (FIOCRUZ, 2005).

Ressalta-se que o movimento pró-mudança precedeu o curso de ativação de mudanças, como foi demonstrado anteriormente. Na verdade, foi a partir das experiências acumuladas pelos atores envolvidos com o movimento prómudança que se organizou o curso de ativação de mudanças. Vinte e oito autores, pertencentes a este movimento, organizaram o curso embasados no perfil de competência do ativador de mudanças identificado pela ampla investigação qualitativa da prática de atores envolvidos em experiências positivas de mudança (FIOCRUZ, 2005).

O perfil do ativador possui três áreas de competência: Político-gerencial, Educacional e Cuidado à saúde. Foi na intersecção dessas três áreas que surgiu o campo de atuação do ativador, o campo de ativação de processo de mudança (FEUERWERKER; LIMA, 2004).

A formação profissional orientada por competências, o currículo integrado, o processo de ensino-aprendizagem com abordagem construtivista, o uso de metodologias ativas de ensino-aprendizagem e da educação à distância, com avaliação formativa e educação permanente dos professores, foram as diretrizes e pressupostos balizadores do Projeto Político Pedagógico do Curso de Ativação de Mudanças (FEUERWERKER; LIMA, 2004). O curso trabalhou com 
momentos presenciais e à distância, que se constituíram em espaços para reflexão e exercício da capacidade crítica, favorecendo a troca de experiências e ampliação de saberes, desenvolvendo ferramentas nas áreas de competência (LIMA, 2007).

Durante o processo seletivo dos especializandos, houve mudança de ministro da Saúde e das equipes de coordenação do DEGES e da SGTES. Os novos gestores optaram por retomar, em grande parte, experiências anteriores de incentivo às mudanças na formação como o PROMED. No final de 2005, esse retorno gerou o PRÓ-SAÚDE, que se limitava aos cursos de enfermagem, odontologia e medicina. Nesse novo cenário, o AprenderSUS passou a ter suas estratégias reavaliadas, gerando fortes repercussóes no desenvolvimento do curso, com atrasos em repasses e desgaste da organização do curso. No entanto, com muito trabalho e após uma ampla reorganização orçamentária, devido ao corte de financiamento, o curso ocorreu e mudanças começaram a ser implantadas por todo o país.

Ainda em 2004, um novo ator surge neste complexo cenário: o Fórum Nacional de Educação das Profissões na Área da Saúde (FNEPAS), que articula entidades envolvidas com a formação e desenvolvimento dos profissionais da área da saúde (LIMA; SILVA, 2004). Tem como objetivo contribuir com o movimento pró-mudança, visando à mudança na formação das profissões dessa área, tendo a integralidade em saúde e a educação permanente como os eixos orientadores. O grande diferencial deste ator é que, pela primeira vez, as profissóes da saúde se unem em torno da construção de cenários políticos e institucionais mais favoráveis, buscando mudanças na formação por meio de ações multiprofissionais e do trabalho em equipe (LUGARINHO; FEUERWERKER, 2006).

Esta ação passou a congregar várias outras iniciativas deste amplo e complexo movimento. Não se busca apenas a mudança de uma profissão, mas sim a mudança na formação dos profissionais de saúde. Quando se pensa em trabalho em equipe, temos de ter em mente que os vários membros estão aptos e sabem trabalhar em equipe, não apenas somando, mas potencializando as ações da equipe (AGUIAR; LUGARINHO, 2006).

Lançado em novembro de 2005, o Programa Nacional de Reorientação da Formação Profissional em Saúde (PRÓ-SAÚDE) surgiu como uma ação interministerial dos Ministérios da Saúde e Educação. O PRÓ-SAÚDE foi fortemente baseado no PROMED, porém ampliado aos cursos de odontologia e enfermagem, além das escolas médicas. O PRÓ-SAÚDE também visa a 
aproximar o perfil do egresso às necessidades de atenção básica, traduzidas no Brasil pela estratégia de saúde da família (BRASIL, 2006b).

Neste cenário múltiplo e complexo, a mudança da formação se estrutura em inúmeros processos e tentativas. O Homem éhistórico e precisa olhar para o passado para entender seu presente e planejar seu futuro. Entendendo os movimentos anteriores, faremos das novas experiências tentativas mais próximas do sucesso, além de proporcionar a valorização dos atores que vivenciaram as políticas anteriores. Novas políticas públicas pró-mudança na formação necessitam ser construídas coletivamente, focando os sujeitos envolvidos, professores, estudantes e usuários do SUS. O apoio a novas lideranças e o estímulo qualificador, não só financiador, é um dos caminhos para a reforma da educação superior em saúde.

\section{Referências}

AGUIAR, A.C.; LUGARINHO, R. A constituição do Fórum Nacional de Educação das Profissões da Área da Saúde e a Avaliação da Formação no contexto de implantação das Diretrizes Curriculares Nacionais para a Graduação em Saúde. In: PINHEIRO, R.; MATTOS, R. A. (Org.). Gestão em redes: práticas de avaliação, formação e participação na saúde. Rio de Janeiro: Cepesc, 2006. p. 289-296.

ALMEIDA, M.J. Educação médica e saúde: possibilidades de mudança. Londrina: EdUEL, 1999. $196 \mathrm{p}$.

ALMEIDA, M.J. et al. Formação dos profissionais de saúde no Paraná e a implantação das diretrizes curriculares nacionais. 2005. Disponível em: <www.observatoriopr.com/biblioteca $>$ Acesso em: 25 dez. 2006.

BLANK de GARCIA, E. Nuevos paradigmas, educación y salud: transición hacia uma educación para la salud desfragmentada en el siglo XXI. Interface: comunicação, saúde, educação, Botucatu, v. 2, n. 2, p. 189-196, fev. 1998.

BLEJMAR, B.; ALMEIDA, M.J. Cambio organizacional y transformación social. In: FEUERWERKER, L.C.M.; LLANOS, M.V.; ALMEIDA, M.J. (Ed.). La educación de los profesionales de la salud em Latinoamérica: teoría y práctica de un movimiento de cambio. Tomo I. Una mirada analítica. Buenos Aires: Lugar Editorial, 1999. p. 17-45.

CARVALHO, R.T. Reflexões sobre as políticas de RH no setor saúde, no contexto da prática política e na expectativa do Estado mínimo. In: ARRUDA, B.K.G. (Org.). A educação profissional em saúde e a realidade social. Recife: Instituto Materno Infantil de Pernambuco, 2001. p. 249-261.

CECCIM, R.B. Inovação na preparação de profissionais de saúde e a novidade da graduação em saúde coletiva. Boletim da saúde, Porto Alegre, v. 16, n. 1, p. 9-38, 2002. 
CECCIM, R.B.; CARVALHO, Y.M. Ensino da saúde como projeto da integralidade: a educação dos profissionais de saúde no SUS. In: PINHEIRO, R.; CECCIM, R.B.; MATTOS, R.A. (Org.). Ensinar saúde: a integralidade e o SUS nos cursos de graduação na área da saúde. Rio de Janeiro: Cepesc, 2005. p. 69-92.

CHAVES, M.M. Algumas reflexōes sobre IDA: antecedentes do ideário UNI. Divulgação em saúde para debate, Rio de Janeiro, n. 9, p. 5-9, ago. 1994.

CHRISTOFARO, M.A. A organização do sistema educacional brasileiro e a formação na área de saúde. In: SANTANA, J.P.; CASTRO, J.L. (Org.) Capacitação em desenvolvimento de recursos humanos de saúde: CADRHU. Natal: EDUFRN, 1999. p. 185-213.

FAGUNDES, N.C.; FRÓES BURNHAM, T. Discutindo a relação entre espaço e aprendizagem na formação de profissionais de saúde. Interface: comunicação, saúde, educação, Botucatu, v. 9, n. 16, p. 105-114, set. 2004/fev. 2005.

FEUERWERKER, L.C.M. Mudanças na educação médica e residência médica no Brasil. São Paulo: HUCITEC/REDE UNIDA, 1998. 190 p.

FEUERWERKER, L.C.M. Algumas reflexões sobre o desenvolvimento do Programa UNI. Divulgação em saúde para debate, Rio de Janeiro, n. 22, p. 63-70, dez. 2000.

FEUERWERKER, L.C.M.; MARSIGLIA, R. Estratégias para mudanças na formação de RHs com base nas experiências IDA/UNI. Divulgação em saúde para debate, Rio de Janeiro, n. 12, p. 24-28, jul. 1996.

FEUERWERKER, L.C.M.; SENA, R.R. Contribuições ao movimento de mudança na formação profissional em saúde: uma avaliação das experiências UNI. Interface: comunicação, saúde, educação. Botucatu, v.6, n.10, p.37-50, fev. 2002.

GARRAFA, V. Saúde x educação ou saúde + educação? Divulgação em saúde para debate, Rio de Janeiro, n. 22, p. 3, jul. 1996.

GIL, C.R.R. et al. Reformulações no ensino da enfermagem: análise e reflexôes de uma experiência em construção. Divulgação em saúde para debate, Rio de Janeiro, n. 15, p. 11-15, nov. 1996.

IVAMA, A.M.; BATISTA, C.V.M.; SILVA, R.M.R. A Universidade está preparando os profissionais para o próximo milênio? Olho mágico, Londrina, v. 3, n. 14, p. 3-4, out./dez. 1997.

KISIL, M. Uma estratégia para a reforma sanitária: a iniciativa UNI. Divulgação em saúde para debate, Rio de Janeiro, n. 22, p. 5-14, jul. 1996.

KISIL, M.; CHAVES, M.M. Programa UNI: Uma Nova Iniciativa da Educação dos Profissionais da Saúde. Battle Creek: Fundação W. K. Kellogg, 1994. 140 p.

LAMPERT, J.B. Avaliação do processo de mudança na formação médica. In: MARINS, J.J.N. et al. Educação médica em transformação: instrumentos para a construção de novas realidades. São Paulo: Hucitec, 2004. p. 245-268. 
LEAVELL, H.; CLARK, E.G. Medicina preventiva. Rio de Janeiro: McGraw-Hill do Brasil, 1976. 774 p.

LIMA, A.; SILVA, F.V. Fórum Nacional de Educação das Profissōes na Área de Saúde: a construção coletiva de um ator no movimento das transformações da educação em saúde no Brasil. Jornal da Associação Brasileira de Enfermagem, Brasília, a. 46, n. 4, out-dez. 2004.

LINS, A.M.; CECILIO, L.C.O. O Programa UNI no Brasil: Uma avaliação da coerência no seu processo de formulação e implementação. Interface: comunicação, saúde, educação, Botucatu, v. 2, n. 3, p. 87-106, ago. 1998.

LUGARINHO, R.; FEUERWERKER, L.C.M. O que é o FNEPAS? Boletim da Associação Brasileira de Ensino Médico, Rio de Janeiro, v. 33, n. 3/4, p. 16-17, mai-jul. 2006.

MACHADO, J.L.M.; CALDAS JUNIOR, A.L.; BORTONCELLO, N.M.F. Uma nova iniciativa na formação dos profissionais de saúde. Interface: comunicação, saúde, educação, Botucatu, v. 1, n. 1, p. 147-156, ago. 1997.

MARSIGLIA, R.G. Relação ensino-serviços: dez anos de integração docente assistencial (IDA) no Brasil. São Paulo: Hucitec, 1995. 135 p.

MARTINS, C.B.C. Programas de melhoria e inovação no ensino de graduação: uma avaliação preliminar. Estudos e debates: uma política de ensino superior, Brasília, v. 20, 1999. p. 189-221.

MERHY, E.E.; FEUERWERKER, L.C.M.; CECCIM, R.B. Educación Permanente en Salud: una estrategia para intervenir en la micropolítica del trabajo en salud. Salud Colecti$v a$, Buenos Aires, v. 2, n. 2, p. 147-160, may./ago, 2006.

MORIN, E.; ALMEIDA, M.C.; CARVALHO, E.A. (Org.). Educação e complexidade: os sete saberes e outros ensaios 3. ed. São Paulo: Cortez, 2005. 104 p.

MORIN, E. Os sete saberes necessários à educação do futuro. 11. ed. São Paulo: Cortez; Brasília, DF: UNESCO, 2006a. 118 p.

PEREIRA, L.A.; LOPES, M.G.K.; LUGARINHO, R. Diretrizes curriculares nacionais e níveis de atenção à saúde: como compatibilizar? 2006. Disponível em: <http://www.fnepas. org.br> Acesso em: 13 fev. 2007.

RANGEL, M.L; VILASBÔAS, A.L. Rede UNIIDA: Breve histórico, concepção, organização e estratégias de ação. Divulgação em saúde para debate, Rio de Janeiro, n. 22, p. 15-18, jul. 1996.

ROSCHKE, M.A.; DAVINI, M.C.; HADDAD, J. (Ed.). Educación permanente de personal de salud. Washington: OPAS, 1994. 247 p. (Série Desarrollo de Recursos Humanos, 100).

SAKAI, M.H. et al. Recursos Humanos em Saúde. In: ANDRADE, S.M.; SOARES, D.A.; CORDONI JR., L. Bases da Saúde Coletiva. Londrina: EdUEL, 2001. p. 111-124. 
SANTANA, J.P.; CAMPOS, F.E.; SENA R.R. de. Formação profissional em saúde: desafios para a universidade. In: SANTANA, J.P.; CASTRO, J.L. (Org.). Capacitação em desenvolvimento de recursos humanos de saúde: CADRHU. Natal: EDUFRN, 1999. p. 109-123.

SANTOS, N.R. (Org.). A prática do controle social através dos conselhos de saúde. Divulgação em saúde para debate, Rio de Janeiro, n. 22, p. 71-91, dez. 2000.

SCHMIDT, L.A.T. Os cursos de fisioterapia no Paraná frente aos conceitos contemporâneos de saúde. 2002. 155 f. Dissertação (Mestrado) - Universidade Estadual de Londrina, Londrina, 2002.

SIQUEIRA, B.P. PROMED: Alguns parâmetros adotados para avaliação dos projetos. Boletim da Associação Brasileira de Ensino Médico, n. 6, nov./dez. 2002.

STELLA, R.C.R. Desafios e estratégias para interiorização do trabalho em saúde. In: BRASIL. Ministério da Saúde. Política de recursos humanos em saúde. Brasília: Ministério da Saúde, 2002. p. 74-84.

TANCREDI, F.B. Institucionalização e sustentabilidade: desafios permanentes dos UNI. Divulgação em saúde para debate, Rio de Janeiro, n. 11, p. 5-10, set. 1995.

TEIXEIRA, A. Ensino Superior no Brasil: análise e interpretação de sua evolução até 1969. Rio de Janeiro: FGV, 1989. 212 p.

TEIXEIRA, C.F.; PAIM, J.S. Políticas de formação de recursos humanos em saúde: conjuntura atual e perspectivas. Divulgação em saúde para debate, Rio de Janeiro, n. 22, p. 1923, jul. 1996.

WORLD HEALTH ORGANIZATION. Report of the International Conference on Primary Health Care Alma Ata. Geneva, 1978. (Health for All Series, 1). 79 p. 


\section{Changing movements in health higher education: from community medicine to the activators course}

This paper aims to ponder over the various pro-change initiatives in health higher education in Brazil. A historical analysis is needed since prior experiences systematization and diffusion are important on attempting to build new pro-change proposals. Today we are pondering over active processes of teachinglearning because we have experienced proposals such as Community Medicine, the Professor Integrative Assistence Project, the PROUNI Program, the Rede UNIDA movement, the Curricular Guideline Law, Permanent Education in Health and the Activators' course. There is no need to discover the wheel all the time. It can be adapted and start to spin again. Taking a look into the past experiences and into the present needs helps in building a desirable future.

> Key words: Health Education; Health Policy; Human Resources Formation; Pro-change Movement in Formation. 